\title{
lontophoresis with Potassium lodide, Inedited Palliative Physiatric Method for Hemifacial Spasm-Case Report and Literature Review
}

\author{
Aurelian Anghelescu, Cristina Gorgan, George Petcu and Gelu Onose
}

Teaching Emergency Hospital "Bagdasar-Arseni", University of Medicine and Pharmacy "Carol Davila", Romania

Corresponding author: Aurelian Anghelescu, Senior Consultant Neurologist, Assist Prof, Teaching Emergency Hospital "Bagdasar-Arseni", University of Medicine and Pharmacy "Carol Davila", Neuromuscular Rehabilitation, Berceni Av., No.12, Bucharest, 041915, Romania, Tel: +40720807607; E-mail: aurelian_anghelescu@yahoo.co.uk

Received: Apr 14, 2016; Accepted: May 23, 2016; Published: May 25, 2016

\section{Abstract}

Background: Hemifacial spasm (HFS) is a rare entity, characterized by alternating involuntary twitching (clonic or tonic contractions) of the facial muscles on one side of the face. In most cases the pathophysiological mechanism is represented by a neurovascular conflict.

Methods and findings: The actual case refers to a 62 years old Caucasian woman, with a typical progressive left side HFS, manifested at the age of 55. She was admitted twice (in November 2015 and February 2016) in the rehabilitation department, and investigated for an optimal therapeutic approach. Magnetic resonance angiography (MRA) revealed a mechanical neurovascular conflict, inflicted by an ipsilateral dolichoectatic, compressive vertebral artery. The patient categorically refused the conventional standard therapies (the functional neurolysis with botulinum toxin injections, or the microvascular surgical decompression alternative). She was treated in a conservative manner, using iontophoresis with potassium iodide (KI) applied to the twitched hemiface, for 10 days, in two therapeutic sequences. After the second treatment session, the patient noticed a $47 \%$ global reduction of her disturbances, reflected by the self-assessment questionnaires scores.

Conclusion: Iontophoresis with $\mathrm{KI}$ is an inedited, conservative treatment applied in a typical form of HFS (with vascular compressive etiology), indicated as a therapeutic palliative alternative, to a patient who refused the conventional treatment methodology. It is a cheap procedure, painless, without adverse reactions, repeatable, controllable. The patient had a good compliance and therapeutic satisfactions, although symptoms alleviation was partial and temporary (as long as the trigger persisted).

Keywords: Hemifacial spasm (HFS); Magnetic resonance angiography (MRA); Vertebral artery dolichoectasia; Iontophoresis; Potassium iodide; Palliative

\section{Introduction}

Primary facial hemispasm (HFS) characterized by alternating involuntary twitching (clonic or tonic contractions) of the facial muscles on one side of the face $[1,2]$ is a rare entity, prevalent in 9.8 per 100,000 persons [3]. In most cases the common underling etiology is the ipsilateral vascular compression of the 7 th cranial nerve at its root exit zone (REZ).

\section{Case Report}

A 62-years-old woman, diagnosed at the age of 55 with hemifacial spasm (HFS), was admitted twice in our Clinic Rehabilitation department (during 02/11/2015 - 13/11/2015 and $11 / 02 / 2016-04 / 03 / 2016)$, for an optimal therapeutic approach.

Initially she accused episodic, irregular (mainly clonic, but also tonic), unilateral left hemifacial muscle spasms, vertigo, low-pitched tinnitus on the ipsilateral ear, walking instability, agoraphobia. Her family history was irrelevant (no history of dyskinesia).

Her personal pathological history consisted of: type 2 diabetes mellitus without complications, mixed hyperlipidemia, hypothyroidism and hormone replacement therapy. She had no personal history of facial nerve injury (Bell's palsy, facial trauma, or tumor). The general physical examination revealed no abnormalities.

She related abnormal intermittent, paroxysmal synkinesis starting in November 2009, initially confined to the orbicularis oculi muscle (inducing a distressing, forced closure of the eyeblepharospasm). The ipsilateral involuntary movements gradually progressed and affected her entire left hemiface (during 2013), spreading towards the orbicularis oris muscles, zygomatic, pulling the mouth to the left), then extending topographically down to the platysma (from December 2014).

The progressive evolution of the HFS and the accompanying disturbing symptoms (vertigo, ataxia), progressively interfered with her quality of life (reading, eating); episodically the intensity of dizziness generated distress, anxiety and impairment of the social life (agoraphobia).

Unfortunately, the patient's symptomatology was not alleviated with the usual medication (sedatives and/or anticonvulsant medication: carbamazepine, clonazepam, or gabapentine-all being ineffective, during the evolution). 
The etiologic diagnostic approach is illustrated by the clinical (Figure 1), electrophysiological (brainstem auditory evoked

potentials-BAEPs and visual evoked potentials-VEP, Figure 2) and magnetic resonance (MR) aspects (Figures 3 and 4).
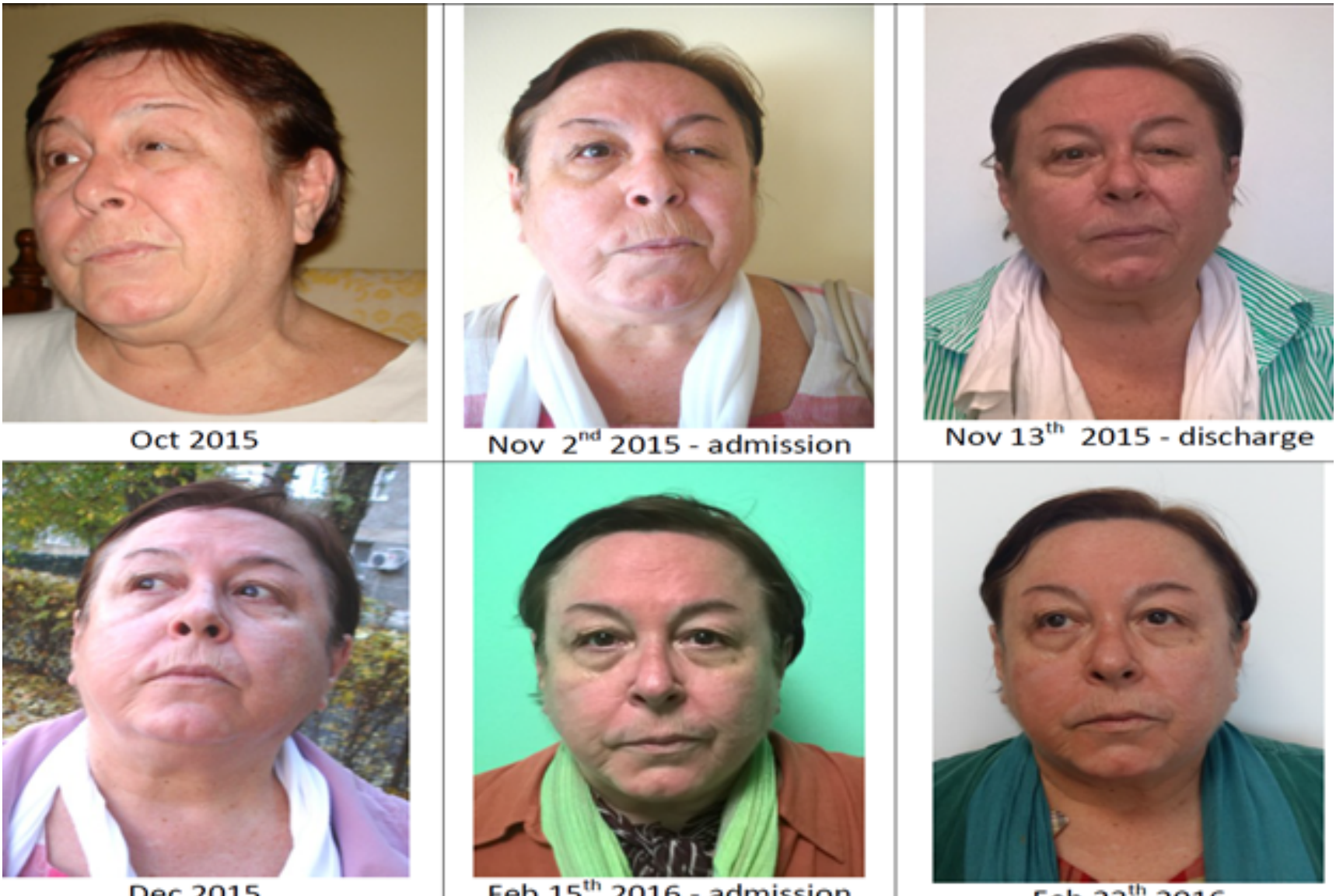

Nov $2^{\text {nd }} 2015$ - admission

Nov $13^{\text {th }} 2015$ - discharge

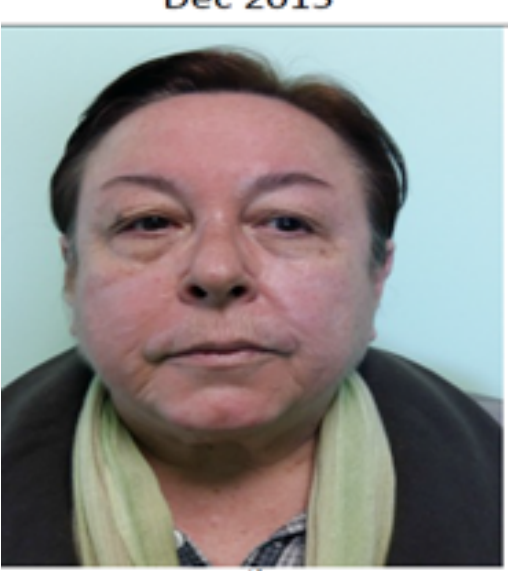

Feb $26^{\text {th }} 2016$
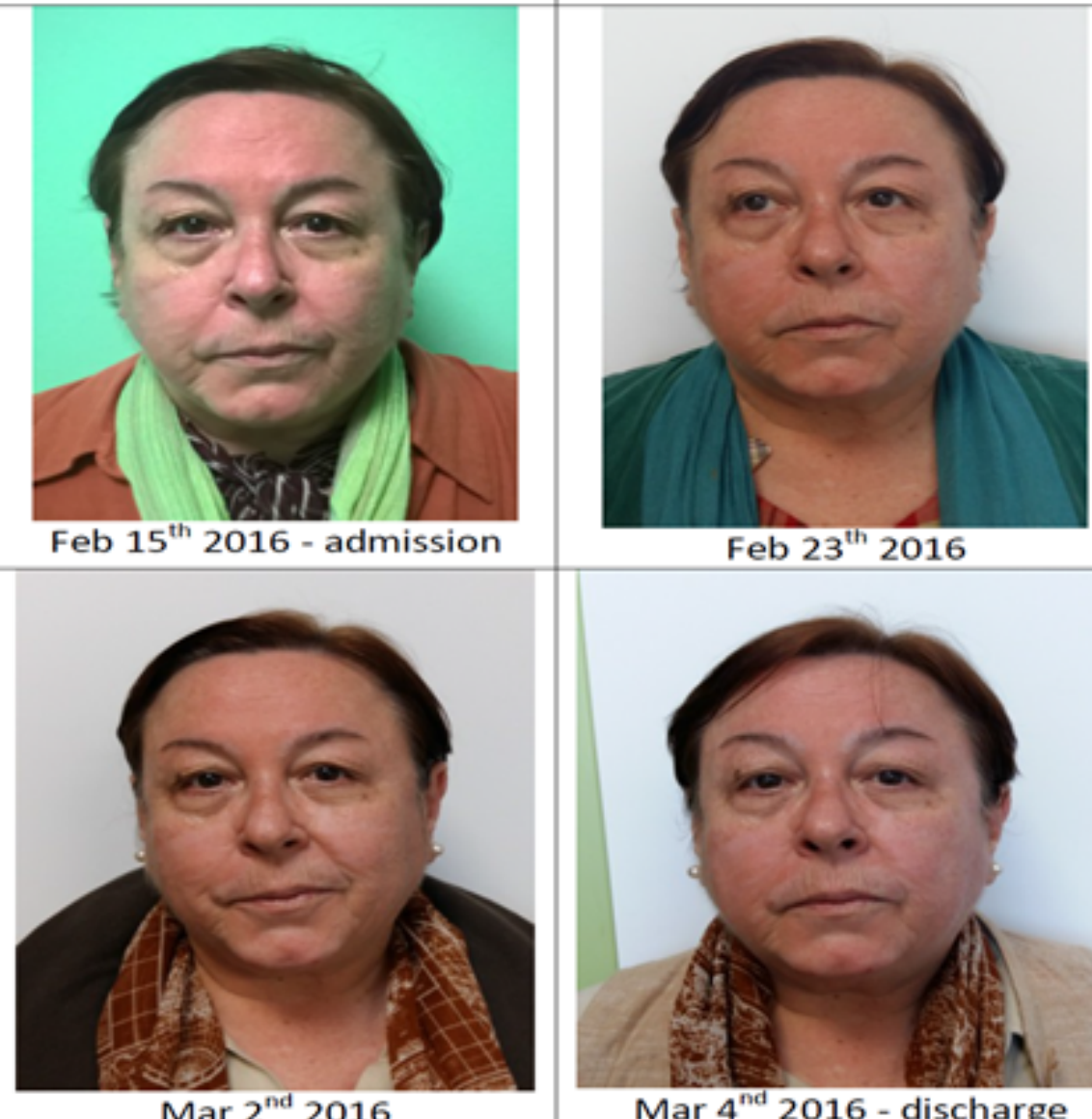

Mar $4^{\text {nd }} 2016$ - discharge

Figure 1 Left HFS, in a 62 years-old woman: pre-treatment aspect (Oct 2015: disfiguring grimace, with involuntary, partial closure of the left eye, lifting of the mouth corner, eyebrow lift, spreading down to the platysma, in a 'tonus phenomenon '). Successive pictures taken during the first and second admission. Symptomatic relief after a voluntary (slight) retrocollis, instinctively adopted as a decompressive posture ("I feel good, when I adopt a proud attitude"- Dec 2015) [Explicit patient consent was obtained to use her images and medical data for scientific purpose]. 


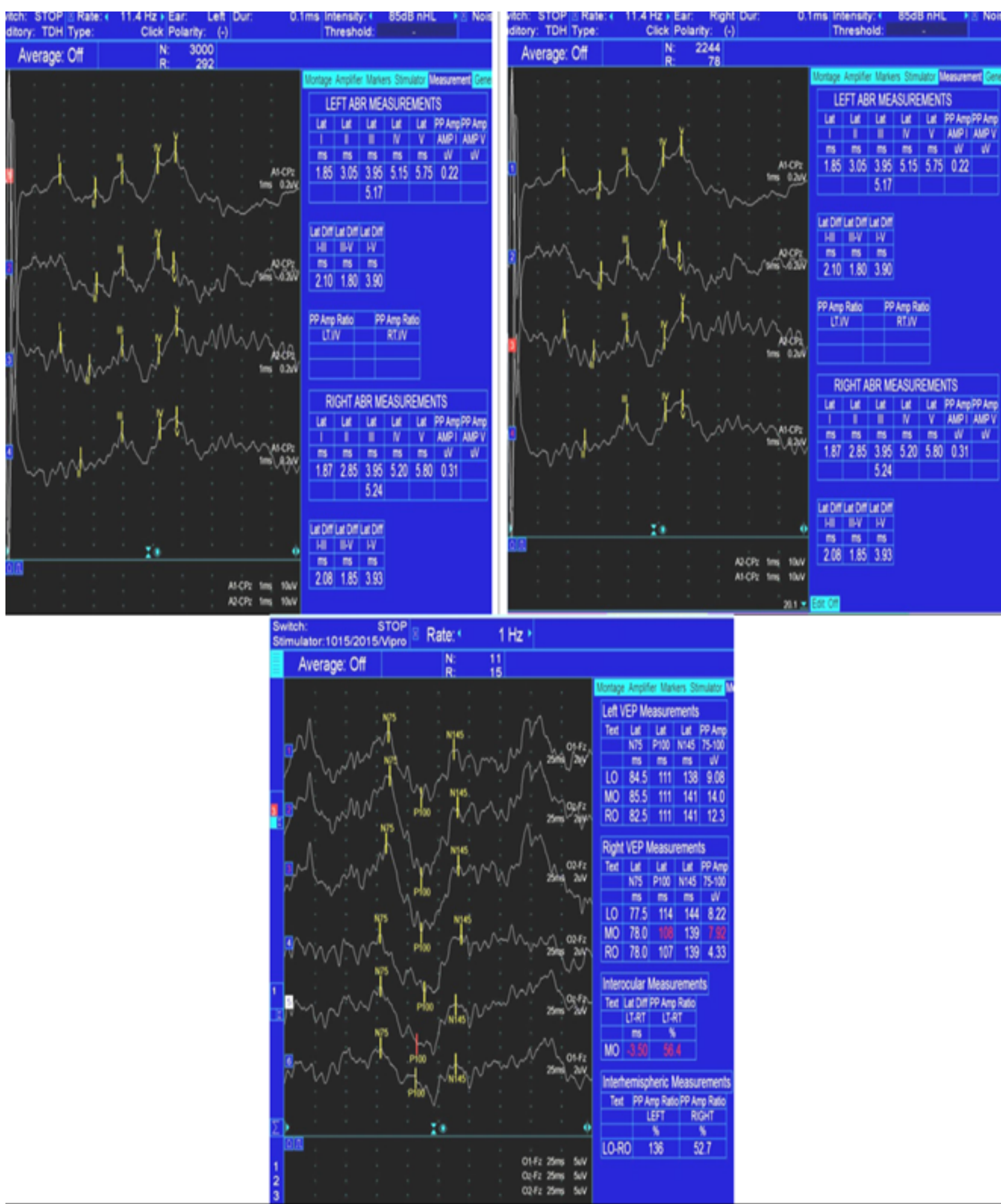

Figure 2 BAEPs latencies are bilaterally normal (up). VEP-pattern reversal N75/P100 complex with normal morphology, amplitude and latencies at both eyes (down). 


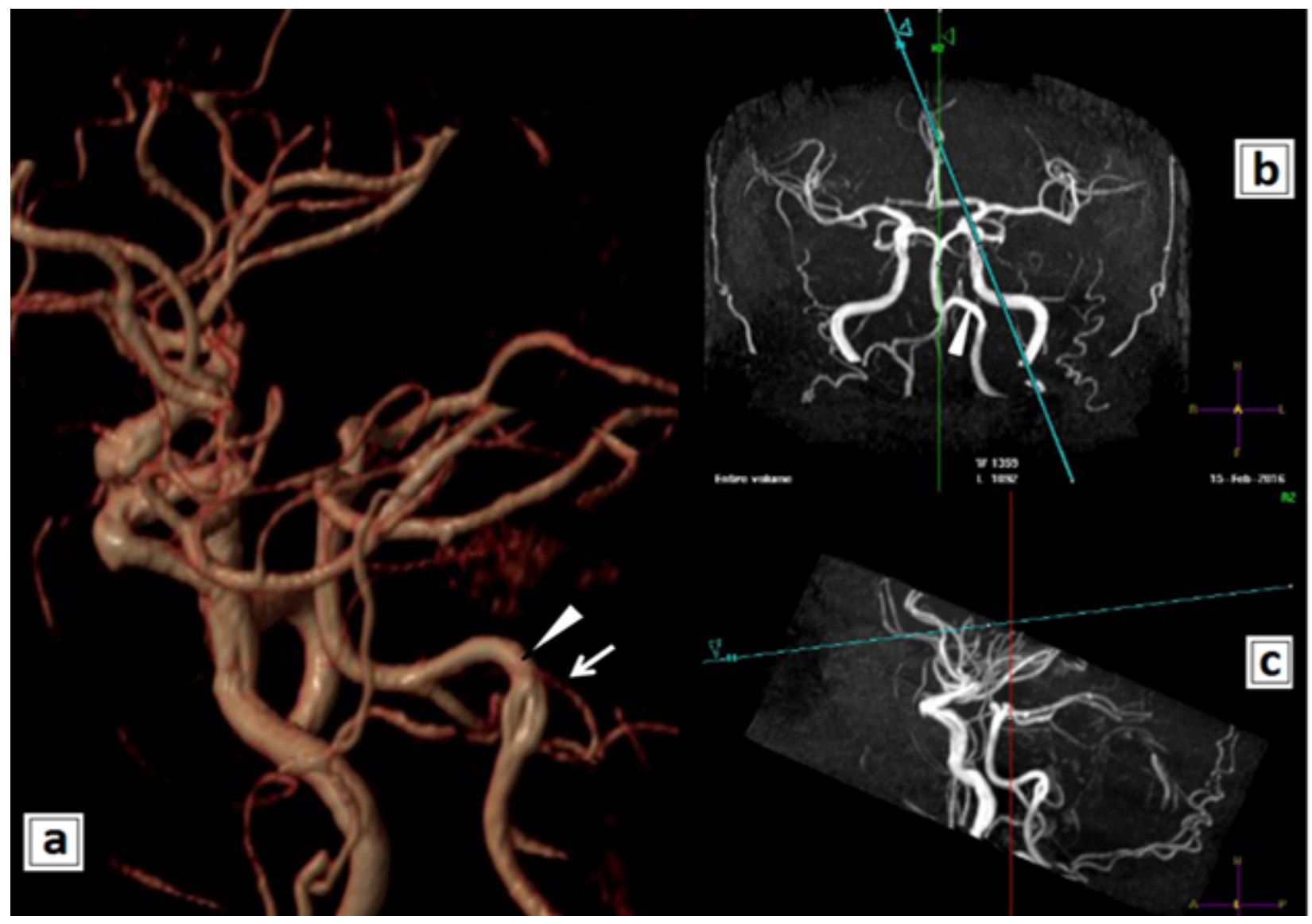

Figure 3 Brain MRI imaging, MRA (a) SVR reconstruction after 3D acquisitions; (b and c) 3D reconstructions MIP. Left Vertebral Artery (LVA) dolichoectasia (diameter $4.7 \mathrm{~mm}$ ) associated with a small fenestration in the V4 segment (double lumen, two separate channels that fuse). VA (white triangle); Anterior Inferior Cerebellar Artery (AICA: white arrow).

The patient refused the other possible (currently applied) therapeutic alternatives for HFS: the functional neurolysis with botulinum toxin injections was postponed, due to economic reasons. She was also informed about the microvascular surgical decompression alternative (MVD), also rejected, because of to her age and associated pathology.

\section{Methods}

Due to the fact that the patient refused the conventional standard therapies, it was applied a cheap, conservative method: iontophoresis with potassium iodide (KI) applied to the twitched hemiface, for 10 days, in two therapeutic sessions (during 02/11/2015 - 13/11/2015 and 11/02/2016 04/03/2016).

Each daily iontophoresis sequence used $2 \mathrm{ml}$ of $1 \%$ aqueous solution of potassium iodide $(\mathrm{Kl}, 0.005 \mathrm{~g} / \mathrm{cm} 2)$, applied at cathode $(2 \times 2 \mathrm{~cm})$, who stimulated the left affected hemiface, using a galvanic current gradually increased to 3 milliamperes, until a light tingling sensation. The anode $(5 \times 5 \mathrm{~cm})$ was applied in the left retroauricular region. The therapy lasts about 30 minutes and there were five consecutive therapeutic sessions each week, and was well tolerated. The patient was carefully investigated to exclude the main theoretical contraindications of iontophoresis (pacemakers, metal orthopaedic implants, cardiac arrhythmia, skin disease or rash, pregnancy).

Advanced Pubmed searches associating two pairs of items ( $\mathrm{KI}$ and HFS, respectively $\mathrm{KI}$ and dyskinesia) were negative.

The physiatric method associated an oral commercial antivertigo pharmacological combination (cinarizinum and dimenhidrinatum), and an OTC with neurotrophic factors (citocoline, Bacopa monnieri, Ginkgo biloba, alfa-lipoic, acid fosfatidilserine) to promote regeneration of the (chronically) damaged neurons in the 7th and 8th cranial nerves complex.

The treatment results were assessed with a typical five-level self-reporting Likert scale of satisfaction, focused on the vestibular subjective disturbances, sleep, synkinesis (before and at the end of the treatment, synthetically presented in Table 1), and the Synkinesis Assessment questionnaire [4] (Table 2). 

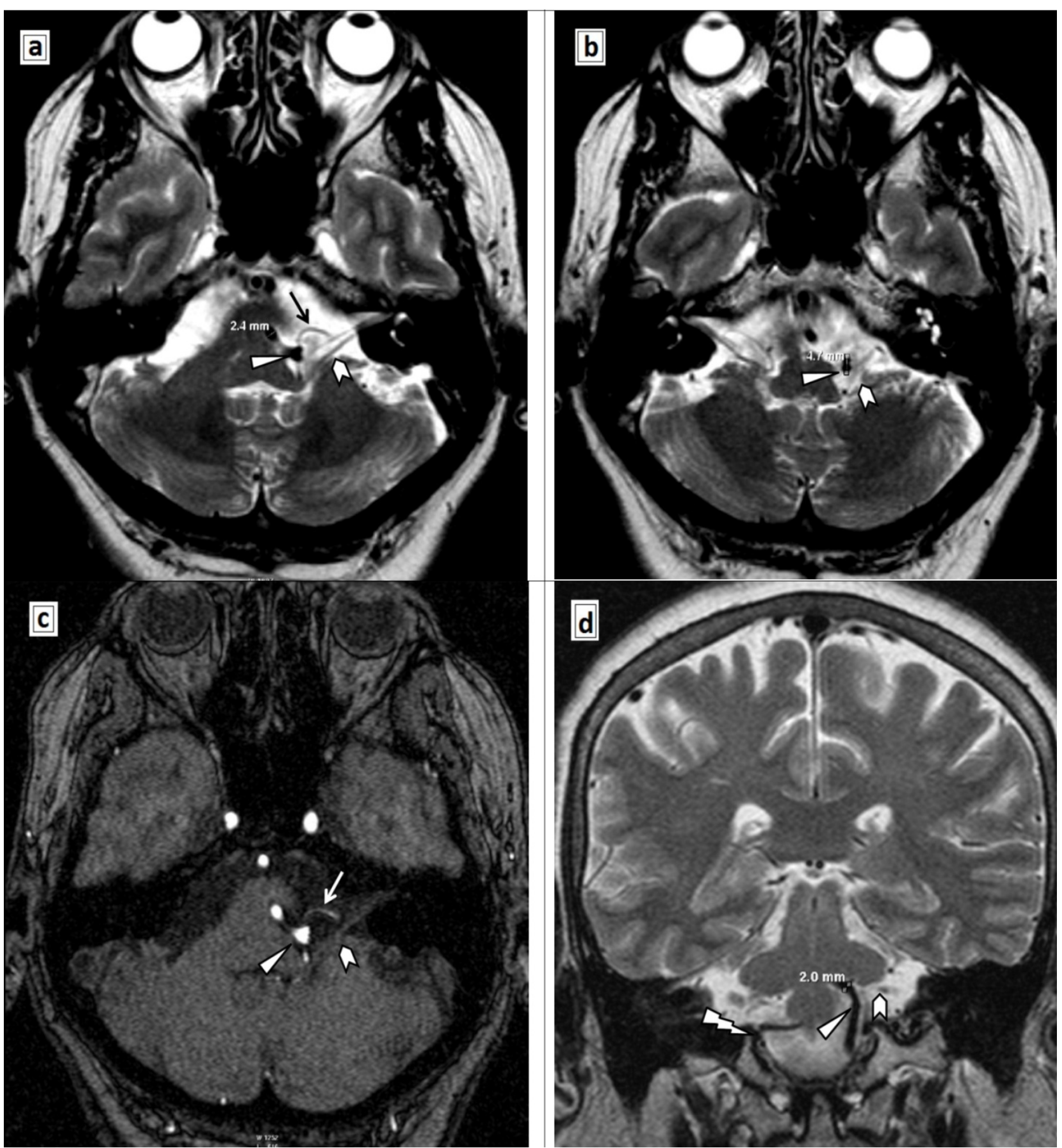

Figure 4 Compressive neurovascular conflict at the emergence of the 7th cranial nerve, in the cerebellopontine angle (white indented arrow). ( $a$ and b) T2 TSE axial scans ( $2 \mathrm{~mm}$ ); (c) 3D TOFF; (d) T2 TSE coronal scan. Left VA dolichoectasia (maximum diameter $4.7 \mathrm{~mm}$ ); left VA (white triangle); right VA (d): "lightning" arrow; loop of the left AICA [(a): black arrow; (c): white arrow)].

All ethical standards were followed. Written informed consent was obtained from the patient for publication, as well as our hospital's Bioethics Commission approval.

\section{Results}

After the first iontophoretic treatment in November 2015, both the patient and doctor noticed a satisfactory global improvement of the aesthetic aspect of the face (the blepharospasm and involuntary contractions decreased in frequency and duration), and also her symptoms (the sleep disturbances, vertigo) improved.

Initially, the overall involuntary facial twitching and the other symptoms globally diminished with $29 \%$; the favorable clinical effect was maintained until the second admission. At the end of the second treatment stage, it was obtained a $47 \%$ 
global reduction of the patient's disturbances, aspects reflected by the global satisfaction scale (Table 1) and the synkinesis self-assessment questionnaire (SAQ) score (Table 2).

Since the second discharge, during the next two months, only a single nocturnal relapse of facial twitching was reported; her sleep is restful, the patient takes daily long walks, is euthymic.

Table 1 Global satisfaction after the physiatric treatment.

\begin{tabular}{|l|l|l|l|l|}
\hline Global satisfaction scale & very satisfied & somewhat satisfied & neutral & not very satisfied \\
\hline $15-\mathrm{Nov}$ & & $\mathrm{N}-\mathrm{d}$ & $\mathrm{N}-\mathrm{a}$ \\
\hline $16-\mathrm{Feb}$ & $\mathrm{F}-\mathrm{d}$ & $\mathrm{F}-\mathrm{a}$ & \\
\hline $\mathrm{N}=$ November 2015; F= February 2015; a= admission; $\mathrm{d}=$ discharge; & \\
\hline
\end{tabular}

Table 2 Synkinesis self-assessment questionnaire (SAQ) score.

\begin{tabular}{|c|c|c|c|c|c|}
\hline & Items & $\mathrm{N}-\mathbf{a}$ & $\mathrm{N}-\mathrm{d}$ & F-a & F-d \\
\hline I & When I smile, my eye closes & 3 & 2 & 2 & 1 \\
\hline II & When I speak, my eye closes & 4 & 3 & 3 & 1 \\
\hline III & When I whistle or pucker my lips, my eye closes & 2 & 1 & 1 & 1 \\
\hline IV & When I smile, my neck tightnes & 5 & 5 & 5 & 5 \\
\hline V & When I close my eyes, my face gets tight & 1 & 1 & 1 & 1 \\
\hline VI & When I close my eyes, the corner of my mouth moves & 5 & 4 & 4 & 3 \\
\hline VII & When I close my eys, my neck tightnes & 5 & 3 & 3 & 1 \\
\hline VIII & When I eat, my eye waters & 4 & 1 & 1 & 1 \\
\hline \multirow[t]{3}{*}{ IX } & When I move my face, my chin develops a dimpled area & 5 & 4 & 4 & 4 \\
\hline & Sum of scores I-IX & 34 & 24 & 24 & 18 \\
\hline & SAQ total Score (sum of scores I-IX)/45x100 & 75.5 & 53.3 & 53.3 & 40 \\
\hline
\end{tabular}

$\mathrm{N}=$ November 2015; F= February 2016; a= admission; $d=$ discharge; (1= seldom or not at all; $2=$ occasionally, or very mildly; $3=$ sometimes, or mildly; $4=$ most of the time, or moderately; $5=$ all the time, or severely)

\section{Discussion}

Our clinical data correlates with the literature information, collected during the last 20 years by Soriano-Baron et al., who reported mainly a left side implication, a female predominance and an average age at onset of 44 years (43.9 ( \pm 11.9$))$ [ 5].

The most effective screening method in HFS is the magnetic resonance angiography (MRA). Usually the HFS results from a chronically neurovascular conflict at the REZ level, but it may have no apparent cause (in idiopathic HFS) [5].

In most cases, the offending vessel is the anterior inferior cerebellar artery (AICA) [5], but there are also other pathological arteries belonging the vertebrobasilar system, culprit for the chronic neurovascular conflict: the posterior inferior cerebellar (PICA) the vertebral artery (VA) the basilar, the superior cerebellar, even an anomalous branch of the ascending pharyngeal artery [6-8]. Direct compression by a dolichoectatic vertebrobasilar artery was noticed in $0.7 \%$ patients [9].
In the present case MRA detected the coexistence of two arteriovenous malformation of the left VA: fenestration in the V4 segment and dolichoectasia. Fenestration is a rare vascular anomaly $(0.23 \%$ to $1.95 \%)$ of the VA, accidentally observed at autopsy or in angiographic studies $[10,11]$. This incidentally revealed anatomic malformation could predict (a possible, future) arterial dissection [11] and stroke, with poor prognosis.

Rarely, HFS could be secondary to a tumoral, demyelinating or inflammatory damage anywhere along its anatomical structure: the pontine nucleus, the intraneuraxial path, (mainly) at the cerebellopontine angle (CPA), or during its trajectory to the internal auditory canal and the stylomastoid foramen. Secondary HFS occurred in only $0.5 \%$ of cases in a large (1,642 patients) case review [9].

The BAEPs and MRI excluded a CPA pathological process: a tumor-related HFS (such as an acoustic neuroma, meningioma, schwannoma, lipoma) [12-14], an epidermoid [15] or arachnoid cyst, arachnoiditis [16], or another posterior fossa tumors (a contralateral foramen magnum meningioma [17], or a ponto-medullary junction proliferation) [18]. 
Lee $\mathrm{SH}$ et al. [13] noticed only 9 cases $(0.4 \%)$ attributable to CPA tumors, in a review of 2,050 subjects with HFS.

Clinical and paraclinical investigations excluded a multiple sclerosis (individuals younger than 40) [19], an autoimmune rheumatic disease [20] (a Sjögren syndrome, rheumatoid arthritis, systemic lupus erythematosus) [21] or a vascular malformation of the brainstem (pontine carvernoma) [22].

The first therapeutic choice, proposed to our elderly patient for her HFS, was the minimum-invasive intervention with Botulinum toxin. Due to its transient improvement effect and economic reasons (it is expensive and repeated injections could be required every 3 to 6 months), the patient refused this option.

The patient was informed that the microvascular decompression (MVD) can relieve pressure on the facial nerve, and is the only treatment who could offer the prospect of a definitive cure for the HFS, with $80 \%$ excellent to good reported long-term results, and $10 \%$ recurrence rate [5].

Although the chronically neurovascular conflict is believed to be the cause of HFS, the physiopathological mechanisms of the disorder remains unclear.

The literature noticed that the mean blood flow velocity, averaging across the two vertebral arteries was higher on the side of the HFS [23], aspect supposed also in our case, due to the tortuosity of her left dolichoectatic vertebral artery, and the favorable clinical effect of an instinctively adopted decompressive posture (a slight left cervical retrocollis, Figure 1).

There are three different hypotheses about the HFS: the central theory (postulates the reverberant activity and hyperexcitability of the facial motor nucleus [24,25]), the peripheral one (advocates the ectopic activity or ephaptic transmission, between the slight "denuded" 7th nerve axons at the site of the vascular pulsatory, chronic, repetitive, microcompressive irritation) [25-27], and the dual pathology (combines the above two, because the central and peripheral theories are not mutually exclusive) [27]. The dual pathology hypothesis is based on the neuroplasticity of the brain; the chronic neurovascular conflict can induce related structural focal reorganizations in the brain gray matter volume of the right inferior parietal lobule and the cerebellar lobule VIII (when compared with healthy subjects) [28].

Most of the HFS cases are noticed in the middle age, suggesting a long process of abnormal attrition at the neurovascular interface, source for the ectopic action potentials, "sparked" by the focal demyelinated nerve fibers. These aberrant action potentials could be triggered either by the sympathetic endings in the adventitia of the offending artery wall [27], or by axono-axonal "crosstalk" [25-27].

The clinical benefit of the medication with vestibular tropism sustained the supposition of a non-synaptic lateral spread of activity between the peripheral demyelinated adjacent nerve fibers of the 7th and 8th cranial nerves, chronically irritated by the pulsatory vascular conflict. The association of auditory and vestibular symptoms was noticed in $17.5 \%$ cases (from a series of 74 reported) [24].

The mechanism of ectopic action potentials emerged from the demyelinated facial nerve fibers could be associated with the upregulation of the neuronal isoform NaV1.8 [29] (a tetrodotoxin-resistant voltage-gated sodium ion channel epitope). The voltage-gated sodium ( $\mathrm{NaV}$ ) channels play a critical role in initiation and propagation of electrical signals in excitable cells, such as neuronal and muscle tissues.

It can be speculated that transdermal iontophoresis with $\mathrm{KI}$ (transitory and indirectly) rebalanced the physiopathological repercussions on the electrolytes gradient concentration and membrane potential, triggered by the dysfunctional $\mathrm{NaV}$, modulating the aberrant electrogenesis emerged from the vascular morphofunctional "aggression" upon the 7th nerve. Evidently, the favorable effect was not a direct one, but integrated in complex nervous loops (different kind of receptors from the skin, facial muscles, trigeminal sensitive nucleus interconnected with the motor facial nerve, upper modulating influences).

Due to the mollification results obtained, iontophoresis with $\mathrm{KI}$ was the patient's main option, in the specific frame of previous pharmacological limitations, economic restrictions and medical contraindications.

Obvious, this non-invasive treatment has not the complications noticed (sometimes) after the MVD interventions: ischemic brain stem stroke, subdural, cerebellar or even supratentorial subdural hematoma, dural arteriovenous fistula, hearing deficit (permanent or transient), facial palsy (permanent or transient), residual hemifacial spasm, or even mortality [5,30-32].

Prognosis quoad vitam could be compared with the "sword of Damocles", hanging above the patient's future evolution (compromised by the constant fear for stroke).

\section{Conclusion}

The article makes rationale suppositions about the efficiency (partial and temporary) of iontophoresis with $\mathrm{KI}$, applied to a patient with a medically refractory HFS (with vascular compressive aetiology), who refused the conventional treatment methodology. Iontophoresis with $\mathrm{KI}$ represents an inedited palliative therapeutic procedure, cheap, painless, without adverse reactions, repeatable and controllable. The patient had a good compliance and therapeutic satisfactions, although symptoms alleviation was partial and (evidently) temporary, conforming to a famous Latin expression "Sublata causa tollitur effectus": remove (by MVD) the cause, and the effect will cease (in most of the cases).

\section{Consent}

Written informed consent was obtained from the patient for publication, as well as our hospital's Bioethics Commission approval. Copies of both documents are available for review by the Editor-in-Chief of this journal. 


\section{Conflict of Interest}

None

\section{Funding}

None

\section{Author's Contribution}

ANGHELESCU Aurelian-identified the case report and followed up the patient, reviewed the literature and was the major contributor in writing the manuscript.

GORGAN Cristina-electrophysiological data (acquisition, analysis)

PETCU George-MRI and MRA data (acquisition, analysis).

ONOSE Gelu-Approved the final manuscript.

\section{Acknowledgement}

Mrs. Neculae Mariana, physiatrist assistant.

\section{References}

1. Jannetta PJ, Abbasy M, Maroon JC, Ramos FM, Albin MS (1977) Etiology and definitive microsurgical treatment of hemifacial spasm. Operative techniques and results in 47 patients. Journal of Neurosurgery 47: 321-328.

2. Wang L, Hu X, Dong H, Wang W, Huang Y, et al. (2014) Clinical features and treatment status of hemifacial spasm in China. Chin Med J (Engl) 127: 845-849.

3. Nilsen B, Le KD, Dietrichs E (2004) Prevalence of hemifacial spasm in Oslo, Norway, Neurology 63: 1532-1533.

4. Kleiss IJ, Beurskens C, Ingels K, Marres H (2015) Synkinesis assessment in facial palsy: validation of the Dutch Synkinesis Assessment Questionnaire, Acta Neurol Belg.

5. Soriano BH, Vales HO, Arvizu SE, Moreno JS, Revuelta GR (2015) Hemifacial spasm: 20-year surgical experience, lesson learned. Surg Neurol Int 6: 83 .

6. Batten RL, Wan Fai Ng (2014) Facial nerve compression by the posterior inferior cerebellar artery causing facial pain and swelling: a case report. J Med Case Rep 8: 105

7. Mathur T, Srivastava T, Sardana V, Jain R (2013) Atypical hemifacial spasm due to vertebral artery dolichoectasia: rare cause of a rarer clinical entity, BMJ Case Rep 2013: bcr2013010199.

8. Thomas KL, Hughes MA, Frederickson AM, Branstetter BF 4th, Vilensky JA, et al. (2014) Hemifacial spasm caused by an aberrant jugular branch of the ascending pharyngeal artery. $\mathrm{Br}$ Neurosurg 18: 1-3.

9. Han IB, Chang JH, Chang JW, Huh R, Chung SS (2009) Unusual causes and presentations of hemifacial spasm. Neurosurgery 65 : 130-137

10. Ozpinar A, Magill ST, Davies JM (2015) Vertebral artery. Fenestratio Cureus 7: e245.
11. Drapkin AJ (2000) The double lumen: a pathognomonic angiographic sign of arterial dissection? Neuroradiology 42: 203-205.

12. Chang CS, Chuang CC, Wu MF, Liu WS, Tu HT, et al. (2012) Gamma Knife surgery for hemifacial spasm related to cerebellopontine angle tumors. J Neurosurg 117: 170-174.

13. Lee SH, Rhee BA, Choi SK, Koh JS, Lim YJ, et al. (2010) Cerebellopontine angle tumors causing hemifacial spasm: types, incidence, and mechanism in nine reported cases and literature review". Acta Neurochir (Wien) 11150: 1901-1908.

14. Doherty CM, Briggs G, Quigley DG, McCarron MO (2014) An unusual cause of hemifacial spasm. Br J Neurosurg 24: 1-3

15. Alemdar M (2012) Epidermoid cyst causing hemifacial spasm epidermoid cyst in cerebellopontine angle presenting with hemifacial spasm, J Neurosci Rural Pract 3: 344-346.

16. Ruiz JF, Vargas A, González RR, Garcia LR (2015) Hemifacial spasm caused by a cerebellopontine angle arachnoid cyst. Case report and literature review. Neurocirugia (Astur) 26: 307-310.

17. Matsuda $M$, Akutsu $H$, Yamamoto $T$, Ishikawa $E$, Matsumura $A$ (2016) Hemifacial spasm associated with contralateral foramen magnum meningioma: case report. World Neurosurg pp: S1878S 8750 .

18. Castiglione M, Broggi M, Cordella R, Acerbi F, Ferroli P (2015) Immediate disappearance of hemifacial spasm after partial removal of ponto-medullary junction anaplastic astrocytoma: case report. Neurosurg Rev 38: 385-390.

19. Tacconi P, Peltz MT, Lorefice L, Marrosu MG, Marrosu F (2015) Facial synkinesis as a first symptom of multiple sclerosis. Mult Scler pii: 1352458515584415.

20. Birnbaum J (2015) Facial weakness, otalgia, and hemifacial spasm: A novel neurological syndrome in a case-series of 3 patients with rheumatic disease. Medicine (Baltimore) 94: e1445

21. Wu K, Christodoulou L, Siddiqui A, D'Cruz D, Andrews T (2015) Bilateral reversible basal ganglia changes associated with dystonia and hemifacial spasms in central nervous system lupus. Quant Imaging Med Surg 5: 928-929.

22. Man BL, Fu YP (2014) 'Twenty-four-and-a-half' syndrome and contralateral hemifacial spasm due to pontine carvernoma. BMJ Case Rep pii: bcr2013203268.

23. Perren F, Magistris MR (2014) Is hemifacial spasm accompanied by hemodynamic changes detectable by ultrasound? Acta Neurochir (Wien) 156:1557-1560.

24. Wilkinson MF, Kaufmann AM (2014) Facial motor neuron excitability in hemifacial spasm: A facial MEP study. Can J Neurol Sci 41: 239-245.

25. Choi SI, Kim MW, Park DY, Huh R, Jang DH (2013) Electrophysiologic investigation during facial motor neuron suppression in patients with hemifacial spasm: possible pathophysiology of hemifacial spasm: a pilot study. Ann Rehabil Med 37: 839-847.

26. Kameyama S, Masuda H, Shirozu H, Ito Y, Sonoda M, et al. (2016) Ephaptic transmission is the origin of the abnormal muscle response seen in hemifacial spasm. Clin Neurophysiol 127: 2240-2245.

27. Dou NN, Zhong J, Zhou QM, Zhu J, Wang YN, et al. (2015) The mechanism of hemifacial spasm: a new understanding of the offending artery. Neurol Res 37: 184-188. 
28. Tu Y, Yu T, Wei Y, Sun K, Zhao W, et al. (2015) Structural brain alterations in hemifacial spasm: A voxel-based morphometry and diffusion tensor imaging study. Clin Neurophysiol pii: S1388-2457.

29. Xia L, Dou NN, Zhong J, Zhu J, Wang YN, et al. (2014) Upregulation of Nav1.8 in demyelinated facial nerves might be relevant to the generation of hemifacial spasm. J Craniofac Surg 25: $1334-1336$.

30. Jin Y, Zhao C, Su S, Zhang X, Qiu Y, et al. (2015) Residual hemifacial spasm after microvascular decompression: prognostic factors with emphasis on preoperative psychological state. Neurosurg Rev 38: 567-572.

31. Kim SH, Chang WS, Jung HH, Chang JW (2014) Delayed dural arteriovenous fistula after microvascular decompression for hemifacial spasm. J Korean Neurosurg Soc 56: 168-170.

32. Nozaki T, Sugiyama K, Sameshima T, Kawaji H, Namba H (2016) Supratentorial subdural hematoma following microvascular decompression: a report of four cases. Springerplus 5: 353. 